\title{
Психология
}

УДК 159.9.075

\section{H.B. Коптева}

\section{НЕВОПЛОЩЕННОСТЬ В ИНТЕРНЕТЕ КАК НОВАЯ ФОРМА ТЕХНОЛОГИЧЕСКОГО САМООТЧУЖДЕНИЯ (НА ПРИМЕРЕ СТУДЕНТОВ ГУМАНИТАРНЫХ ВУЗОВ) ${ }^{1}$}

Феномен развоплощения (disembodiment) пользователя информационных технологий в виртуальной реальности, отмеченный первыми представителями киберкультуры, в том числе в качестве особой технологической формы самоотчуждения, не получил необходимого анализа в психологии, что можно связать с традиционно периферийным для нее положением вопроса об отчуждении физического тела. В статье в контексте проблематики самоотчуждения и отчуждения продолжена разработка предложенного нами (Коптева Н.В., Калугин А.Ю., Дорфман Л.Я., 2020) теоретического и эмпирического конструкта невоплощенности в интернете как психологического последствия использования современных информационных технологий. Принятая в качестве его основания концепция невоплощенности ментального «Я» в теле, разработанная английским психиатром Р. Лэйнгом, считается одной из фундаментальных концепций отчуждения физического «Я» в психиатрии. Однако обсуждение автором отстранения шизоида от собственного тела проливает свет на принципиальный для понимания упомянутой новой формы самоотчуждения вопрос об особенностях незавершенных в обоих направлениях экзистенциальных положений воплощения/невоплощения, определяемых социокультурными, технологическими факторами, а также выбором самого человека.

На выборке активных пользователей интернета - студентов гуманитарных вузов (возраст от 17 до 25 лет) - с помощью методики Невоплощенность в интернете (НВИ) выявлены группы, различающиеся выраженностью одноименного показателя. Представлены их психологические портреты с точки зрения специфики паттернов невоплощенности (переживаний бестелесности виртуального «Я», неполноты, вторичности технологического способа бытия, ограниченного интернет-средой) и интернет-зависимости. Эмпирически установлены эффекты невоплощенности на отчуждение студентов в различных сферах жизни (от самих себя, от семьи, в межличностном общении, от учебной деятельности и общества), в спектре модальностей от вегетативности до авантюризма.

Ключевые слова: психологические последствия использования информационных технологий, отчуждение физического «Я», невоплощенность в интернете, самооотчуждение, отчуждение.

DOI: $10.35634 / 2412-9550-2021-31-2-160-169$

\section{Концепция Р. Лэйнга - основа конструкта невоплощенности в интернете как психологического последствия, производного от особенностей информационных технологий. Измерения конструкта}

Маршалл Маклюэн, которого называют самым важным мыслителем после Ньютона, Дарвина, Фрейда, Эйнштейна и Павлова [7], первым обратил внимание на последствие применения информационных технологий, в его время еще ограниченных радио, телефоном и телевидением, - отстранение пользователя от своего физического тела. Теоретик медиа неоднократно подчеркивал, что при колоссальной значимости этого последствия, которое, как он полагал, полностью меняет психологию людей, оно так и осталось незамеченным [2]. С появлением персональных компьютеров и интернета ситуация радикально изменилась. В обширной литературе нашло отражение не только киберкультурное развоплощение (cybercultural (dis)embodiment) [21], но и формирование в некоторых случаях на его основе отчуждения пользователей от своих «не годящихся для путешествий в виртуальную реальность тел», сопровождавшееся ненавистью к телу - смесью недоверия и презрения к неуклюжей плоти, «ответственной» за коэффициент сопротивления в технической среде [5]. Однако соответствующую психологическую проблематику в то время лишь отчасти затронули исследования, посвященные множественной, динамичной виртуальной идентичности, играм с нею, мотивам создания и т. д. (Turkle, 1984, 1995; Stone, 1996; Suler, 1997; Reid, Deaux, 1996; Marwick, 2005).

Быстрые темпы распространения и трансформация самих технологий между тем делали присутствие в виртуальном пространстве привычным, дематериализация в нем пользователя начинала казать-

\footnotetext{
${ }^{1}$ Исследование выполнено при финансовой поддержке РФФИ в рамках научного проекта № 19-29-07046.
} 
Невоплощенность в интернете как новая форма технологического самоотчуждения...

161 СЕРИЯ ФИЛОСОФИЯ. ПСИХОЛОГИЯ. ПЕДАГОГИКА

ся чем-то само собой разумеющимся, а новые мультимедийные, аудиовизуальные технологии позволяли потребителям создавать разнообразные цифровые «тела», органичность которых технической среде сглаживала отмеченные Марком Дери некогда острые противоречия между «софтом» разума и «железом» тела, в которое он инсталлирован [5]. В психологии новый феномен так и не получил должного анализа, в большинстве современных работ можно встретить лишь дежурные упоминаниями об ограниченности физического присутствия, бестелесности и анонимности виртуального «Я».

Одна из причин этого положения - дефицит фундаментальных психологических концепций, которые можно было положить в основание изучения нового феномена. Н.А. Каминская указывает на сложившуюся традицию относить явления отчуждения физического «я» к периферийным для психологии областям нейропсихологии или психиатрии. Среди подобных исследований она, в частности, называет принадлежащие Р. Лэйнгу [8].

Фундаментальная концепция онтологической неуверенности Р. Лэйнга $[11 ; 24]$, которую с полным правом можно назвать концепцией невоплощенности (unembodiement) ментального «Я» в теле («The Divided Self. An Existential Study in Sanity and Madness», 1960), создана на материале психопатологии (шизоидной и шизофренической). Тем не менее, это исследование является нетипичным для традиционной психиатрии. Автор - экзистенциальный психолог, феноменолог, опираясь на пионерские разработки проблематики телесности в философии (М. Мерло-Понти, Ж.-П. Сартра), рассматривает воплощение и невоплощение как незавершенные в обоих направлениях экзистенциальные положения, оценку которых с точки зрения нормы и патологии считает неуместной, ставя во главу угла вопросы об их причинах и следствиях. Среди факторов развоплощения Р. Лэйнг, помимо отчуждения в жизни общества, затрагивающего семью, которому уделяет внимание как свойственному его времени, упоминает также некогда господствовавший христианский идеал разъединения души и тела, побуждавший человека выпутывать себя из тела и тем самым достигать желаемого состояния невоплощенной духовности [11. С. 61].

Э. Фромм солидаризируется с Лэйнгом [19. С. 305], когда вместо наклеивания ярлыков (шизоидный, нарциссический, аутический) обращается к приобретавшим все большую актуальность технологическим факторам развоплощения. Предельно отчужденный человек, в силу «общей ориентации на все искусственное, на вторую рукотворную реальность, отрицающей все естественное, природное как второсортное», который утратил чувственное восприятие своего тела и процессов, в нем протекающих, получает у Э. Фромма наименование «кибернетическая личность» [19. С. 301]. В качестве ее разновидности можно рассматривать личность, обязанную своим появлением технологиям цифровой эпохи, создавшим неведомую прежде рукотворную реальность - искусственные виртуальные миры, аналоги настоящего мира. Предпочитающий пребывание в них частичный индивид обычно определяется как интернет-зависимый. Однако патологические процессы формирования зависимости представляют собой искажение процессов, обусловливающих использование технологий в норме. Исходя из этого допущения, Е.И. Рассказова, В.А. Емелин, А.Ш. Тхостов предлагают модель психологических последствий нормативного использования технологий, акцентируя внимание на механизмах их влияния на человека [17. С. 25]. В качестве ключевого последствия подобного рода авторы модели выделяют изменение психологических границ пользователя, их расширение и размывание.

Концепция Р.Лэйнга была взята нами за основу конструкта невоплощенности в интернете, также рассматриваемой как психологическое последствие нормативного использования технологии, производное от ее особенностей [10]. Универсальным базовым фактором отчуждения тела, с его промежуточным между «Я» и «не-Я» положением, согласно Р. Лэйнгу является угроза извне, которой нельзя избежать иным путем. Представляется, что прообразом отчуждения в животном мире можно считать аутотомию (отбрасывание частей собственного тела) - защитный механизм, наряду с более известными - подчинением, борьбой и бегством [9]. Специфику частичной невоплощенности, соответствующий ей характер связи с другими людьми и миром Р. Лэйнг проясняет на примере шизоида, личностного типа, пограничного между нормой и патологией. В отличие от многих «обычных» людей, у которых состояние невоплощенности является временной реакцией на специфическую ситуацию повышенной опасности, шизоид, испытывающий постоянный риск уничтожения собственного «Я» в силу особой уязвимости к отчуждению в отношениях, кладет подобное разъединение в основу способа бытия. Пытаясь спасти от окружающих хотя бы часть себя, он отделяет «истинное» ментальное «Я» от «Я» ложного, защитной личины, соотносимой с телом и поведением. «Отделение "я" от тела препятствует прямому участию невоплощенного “я” в любом аспекте жизни этого мира, который опосредован исключительно 
благодаря телесному восприятию, чувствам и действиям» [11. С. 63]. Раскол «Я» находит свое продолжение в расколе лишенного объективной экзистенции внутреннего «Я» с миром, в положении, которое Р. Лэйнг определяет заимствованным у С. Кьеркегора понятием «заколоченность».

Хотя отчуждение физического «Я» в цифровом обществе является неизбежным психологическим последствием самих информационных технологий, его невозможно рассматривать изолированно от пользовательской активности, места, которое в жизни человека занимает новая среда обитания - киберпространство. Шкалы «Предпочтение интернета» вполне органичны для методик диагностики проблемного использования интернета и социальных сетей $[4 ; 18]$, названия которых указывают на тестируемые особенности взаимодействия людей с технологиями. При этом близкая к ним по смыслу шкала «Психологическая зависимость» присутствует и в методике оценки изменения психологических границ при пользовании техническими средствами (МИГ-ТС) [18], восходящей к упомянутому конструкту нормативных последствий их применения. От шкалы собственно интернет-зависимости ее (как нашу «обычную» привязанность к компьютеру в широком смысле слова) отличает лишь неполнота симптоматики. Измерение конструкта невоплощенности в интернете, выраженность которого соответствует степени заколоченности пользователя во вторичной, искусственной реальности и, соответственно, отчуждения от реальности первичной, получило название «Предпочтение интернета».

Следствием отчуждения телесного «Я» пользователя являются переживания онтологической неуверенности: ощущение утраты реальности, жизненности, субстанциональности не только себя самого, но и других людей, иллюзорности бытия и всего существующего. В нее вносит вклад не только оставленное перед экраном монитора собственное тело пользователя, бестелесный способ его существования в киберпространстве, но и аналогичный статус пребывания в нем других людей. Соответствующую причину онтологической ненадежности компьютерной виртуальной реальности (ontological untrustworthiness of cyberspace) Г. Райнгольд раскрывает, приводя замечание исследователя, уроженца Индии о том, что «видео ... не передает “прану”, жизненную силу, буквально дыхание других людей» [25]. Отчуждение от них, ввиду неполноты представленности онлайн сочетается с самоотчуждением пользователя через отождествление себя с достроенными посредством собственных фантазий образами. Переживания человека, которого суррогат бытия, названный Ш. Теркл «жизнью на экране» (life on the screen) [26], превращает в гиперсознание, составляют содержание измерения конструкта «Невоплощенность как виртуализация».

В понимании Р. Лэйнга шизоидная психопатология является результатом не только социального отчуждения, но и собственной позиции человека, выбора им, вопреки своим страхам, участия в жизни или устранения от прямого контакта с миром. Альтернативное невоплощенности измерение конструкта «Витальность воплощенного “Я”» объединяет взаимосвязанные проявления активности офлайн и характеристики физического здоровья. Шизоидный способ бытия предполагает наличие двух «Я», истинного невоплощенного и ложного, ядром которого является тело. Пользователей информационных технологий можно характеризовать с точки зрения соотношения воплощенного «Я», которому потенциально доступно все многообразие модусов бытия в действительном мире, и развоплощенного, виртуализированного «Я», ограниченного модусами существования, предоставляемыми смоделированной реальностью.

Невоплощенность в интернете как феномен отчуждения физического «Я», порожденный информационными технологиями, является источником серьезных рисков для социализации молодого поколения, которое, как отмечает Марк Дери, сумело найти способ жить с техникой, стать с ней на «ты» [5]. Наиболее широкий доступ к техническим средствам имеет студенчество, отличающееся высоким уровнем цифровой компетентности. Учебно-профессиональная деятельность требует значительного количества времени, проводимого онлайн, и его дальнейшего увеличения с учетом вероятной перспективы расширения дистанционного образования. Студенчество также в значительной мере подвержено информационному отчуждению, усиливающему отчуждение, в частности, в сфере образования. В психологической литературе обсуждаются опасности, которые представляет «использование современными студентами материалов, взятых с сайтов, в качестве конечного и квалифицированного источника информации - без какой-либо проработки, рефлексии и сопоставления» [17. С. 14]. Подобное обучение, в отличие от нацеленного на овладение смыслами, как элементами опыта, видимо, имеет отношение и к технологическому развоплощению, так как затрагивает только интеллектуализированное ментальное «Я» учащихся. 
Невоплощенность в интернете как новая форма технологического самоотчуждения...

Автор критического словаря психоанализа Ч. Райкрофт, определяя отчуждение (alienation) как способ существования или процесс становления, при которых происходит отстранение либо от самого себя (каких-то сторон себя), либо от других, указывает на взаимосвязь самоотчуждения, ограничивающего способность к установлению отношений с другими, и отчуждения от других, ограничивающего способность к самораскрытию [16. С. 118]. В психологических исследованиях показаны взаимопереходы собственно отчуждения в отношении к людям и миру и самоотчуждения как отстранения индивида от разных, в терминах У. Джемса, частей «Я» чистого (К. Хорни, Э. Фромм, К. Роджерс, С. Мадди) и эмпирического (Р. Лэйнг).

Сформулируем конкретные гипотезы исследования. Выраженность невоплощенности как последствия использования интернета у его активных пользователей (студентов) оказывает значимые эффекты

- на ее частные измерения Невоплощенность как виртуализацию, Предпочтение интернета и Витальность воплощенного «Я»; а также

- на интернет-зависимость;

- на отчуждение в разных сферах жизни (от самого себя, от семьи, от других людей, от учебной деятельности, от общества) и модальностях, различающихся мерой его выраженности (вегетативность, бессилие, негативизм, авантюризм).

\section{Организация и методики исследования}

Основную выборку исследования составили 224 человека (20\% - юноши), студенты гуманитарных вузов, в возрасте от 17 до 25 лет.

Использовалась психодиагностическая методика «Невоплощенность в интернете» (НВИ), созданная на основе представленной модели, включающая три субшкалы: Невоплощенность как виртуализация, Предпочтение интернета и Витальность воплощенного «Я», а также общий показатель Невоплощенность в интернете (получаемый при вычитании из суммы двух первых субшкал третьей субшкалы). На конструктную валидность методики указывают результаты анализа главных компонентов и конфирматорного факторного анализа. Одномоментная надежность шкал варьирует от 0,7 до 0,9. Шкалы Витальность воплощенного «Я» и Предпочтение интернета имеют высокий уровень дискриминативности, шкала Невоплощенность как виртуализация - умеренный. Подтверждены внутренняя и внешняя конвергентная и дискриминантная валидности методики [10].

Для диагностики отчуждения применялась разработанная и валидизированная для русскоязычной выборки модификация теста отчуждения С. Мадди, С. Кобэйса и М. Хувера (Maddi S.R., Kobasa S.C., Hoover M. An Alienation Test, 1979) - методика измерения индивидуальной выраженности и структуры субъективного отчуждения (вариант для старших школьников и студентов), ОСОТЧ-У [15], позволяющая установить представленность четырех форм отчуждения (бессилие, вегетативность, нигилизм и авантюризм) по отношению к пяти сферам жизни (общество, учеба, межличностные отношения, семья, собственный внутренний мир), а также генерализированного отчуждения.

Уровень интернет-зависимого поведения устанавливался с помощью тест-шкалы интернетзависимости S.-H. Chen (Chen Internetaddiction Scale - CIAS (2003 г., Китай) [22; 23]) в адаптации В.Л. Малыгина, К.А. Феклисова [13]

\section{Результаты и их обсуждение}

Группы студентов, различающиеся уровнем выраженности общего показателя невоплощенности в интернете, его эффекты на частные измерения невоплощенности, интернет-зависимость и отчуждение.

С помощью кластерного анализа центров K-Mean Claster были выделены три группы респондентов: с высоким (39 человек, 21,9 \% выборки), средним (90 человек, 50,6 \% выборки) и низким, отрицательным (49 человек, 27,5 \% выборки) значением общего показателя методики НВИ (соответственно 14,4; 2,7 и -6,8), см. рис. 1. В двух первых группах показатели НВИ выше, а в третьей - ниже среднего (табл. 2), установленного нами ранее для студенческой выборки $\mathrm{n}=443$ [10].

Студентов с высоким показателем невоплоценности в интернете от студентов со средним показателем в большей мере отличают переживания бестелесности виртуального «Я», неполноты, вторичности технологического способа бытия, ограниченного интернет-средой, к которой их 
сильнее привязывают выгоды опосредствованной коммуникации. Отрицательный показатель невоплощенности в интернете у студентов третьей группы, как будет видно из дальнейшего анализа, указывает на то, что факт бестелесного пребывания в киберпространстве в качестве пользователей технических средств слабо отражается в их переживаниях.

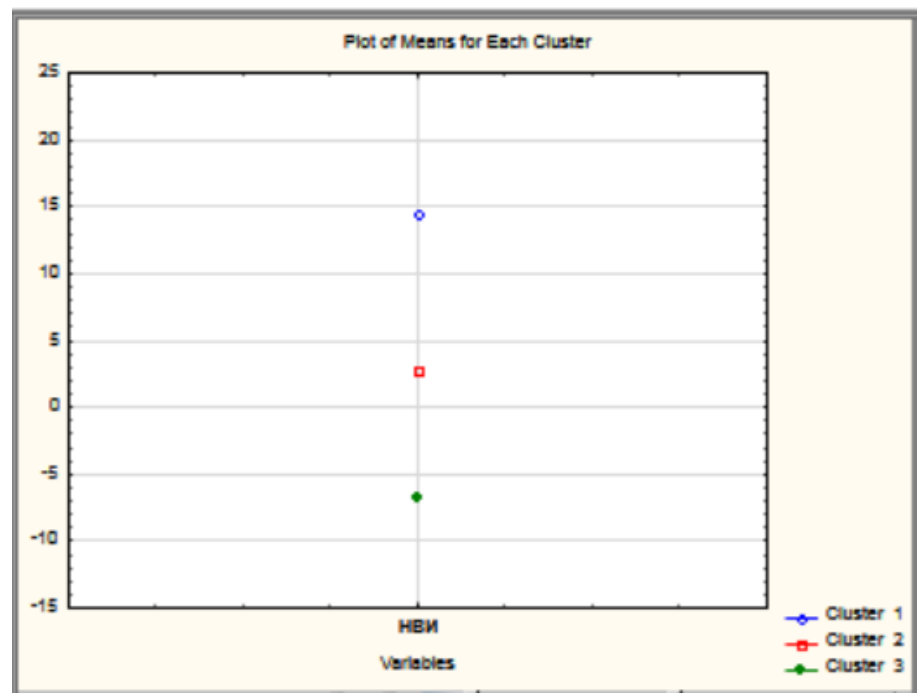

Рис. 1. Группы респондентов, различающиеся выраженностью невоплощенности в интернете

Для более детальной характеристики групп был использован однофакторный дисперсионный анализ (ANOVA). Независимой переменной выступала принадлежность респондентов к одной из трех групп, анализу подвергались частные показатели методики НВИ, а также общий показатель интернет-зависимого поведения (шкалы С.Х. Чена), по которым были установлены значимые эффекты (табл. 1).

Таблица 1

Эффекты невоплощенности в интернете на ее частные измерения и интернет-зависимость

\begin{tabular}{|l|c|c|c|c|}
\hline & MS & MS & \multicolumn{2}{|c|}{ Величины } \\
\hline & Effect & Error & F & p \\
\hline Невоплощенность как виртуализация & 580,3 & 5,79 & 100,3 & 0,000 \\
\hline Предпочтение интернета & 668,2 & 8,54 & 78,3 & 0,000 \\
\hline Витальность воплощенного «Я» & 300,0 & 7,45 & 40,3 & 0,000 \\
\hline $\begin{array}{l}\text { Выраженность интернет-зависимого поведения } \\
\text { (шкала С.Х. Чена). Общий СLАS-балл }\end{array}$ & 4514,6 & 147,18 & 30,7 & 0,000 \\
\hline
\end{tabular}

Нашла эмпирическую поддержку гипотеза о том, что от группы с высоким показателем Невоплощенность в интернете к группе, в которой она представлена на среднем уровне, и группе с отрицательным показателем убывает выраженность частных характеристик Невоплощенность как виртуализации $(14,0 ; 8,6 ; 7,5)$ и Предпочтение интернета $(19,3 ; 15,4 ; 10,9)$, в то время как частная характеристика Витальность воплощенного «Я», напротив, растет $(19,5 ; 21,6 ; 25,0)$ при значимых различиях между всеми группами (табл. 2). Особенности пользовательской активности, помимо шкалы НВИ, определяющей предпочтение интернета в качестве «среды обитания», уточнялись посредством общего показателя интернет-зависимости, CLAS-балла, который оказался максимальным в группе с высоким уровнем Невоплощенности в интернете, промежуточным - в группе со средним и минимальным в группе с низким ее уровнем $(63,9 ; 50,8 ; 44,7)$.

Представим более полно психологические портреты групп студентов как пользователей с точки зрения обсуждаемого статуса в интернете.

Студенты с высоким показателем невоплощенности в интернете проблематизируют свое существование, усматривают в нем сходство со сном, констатируют утрату ощущения реальности, отождествляют себя с персонажами и ролями в киберпространстве, отмечают отстраненность от соб- 
Невоплощенность в интернете как новая форма технологического самоотчуждения...

165 СЕРИЯ ФИЛОСОФИЯ. ПСИХОЛОГИЯ. ПЕДАГОГИКА

2021. Т. 31, вып. 2

ственного тела, поведения, поступков в реальной жизни. Слова Р. Лэйнга, относящиеся к шизоиду, вполне приложимы к этой категории пользователей, невоплощенность которых по своему смыслу совпадает с самоотчуждением: «“я”, более не привязанное к бренному телу, становится, так сказать, “сфантазированным", улетучившимся и превратившимся в переменчивый фантом собственного воображения индивидуума. "Я" не перестало существовать, но оно лишено субстанции, развоплощено, ему не хватает свойства реальности» [11. С. 145]. Переживания невоплощенности как виртуализации «Я» дополняют переживания дефицита витального воплощенного в собственном теле «Я» офлайн, неудовлетворенности своими внешними данными, здоровьем и, в более широком смысле, недостатка способности изменить свою жизнь в лучшую сторону, осуществить мечты, т. е. воплощения как формы инобытия индивидуальности, находящей выражение в процессах воспроизводства, умножения, расширения, продолжения себя [6]. О том, что респонденты «заколачивают» себя в искусственном мире интернета, предпочитая его действительному миру, свидетельствует наиболее высокий в этой группе соответствующий показатель НBИ. Это подтверждает общий CLAS-балл в группе, приближающийся к 65, значению, начиная с которого, по мнению авторов русскоязычной адаптации [13], можно обоснованно констатировать наличие выраженного и устойчивого паттерна интернетзависимого поведения. Очевидно, характер пользовательской активности представителей этой группы имеет непосредственное отношение к выраженности невоплощенности в интернете как новой формы технологического самоотчуждения.

Таблица 2

Количественная характеристика групп по показателям невоплощенности в интернете

\begin{tabular}{|c|c|c|c|c|c|c|}
\hline Характеристики групп & 1 группа & 2 группа & 3 группа & \multirow{4}{*}{1 vs. 2} & \multirow{4}{*}{1 vs. 3} & \multirow{4}{*}{2 vs. 3} \\
\hline $\mathrm{N}$ & 39 & 90 & 49 & & & \\
\hline \% от общей выборки & $21,9 \%$ & $50,6 \%$ & $27,5 \%$ & & & \\
\hline НВИ $(2,5)^{*}$ & $\begin{array}{c}\text { Высокий } \\
\text { уровень } \\
14,4\end{array}$ & $\begin{array}{c}\text { Средний } \\
\text { уровень } \\
2,7\end{array}$ & $\begin{array}{c}\text { Низкий } \\
\text { уровень } \\
-6,8\end{array}$ & & & \\
\hline Невоплощенность как виртуализация $(9,06)^{*}$ & 14,0 & 8,6 & 7,5 & $\mathrm{p}<.001$ & $\mathrm{p}<.001$ & $\mathrm{p}<.01$ \\
\hline Предпочтение интернета $(11,29)$ & 19,3 & 15,4 & 10,9 & $\mathrm{p}<.001$ & $\mathrm{p}<.001$ & $\mathrm{p}<.001$ \\
\hline Витальность воплощенного Я $(21,24)^{*}$ & 19,5 & 21,6 & 25,0 & $\mathrm{p}<.001$ & $\mathrm{p}<.001$ & $\mathrm{p}<.001$ \\
\hline $\begin{array}{l}\text { Выраженность интернет-зависимого поведения } \\
\text { (шкала С.X. Чена). Общий CLAS-балл }\end{array}$ & 63,9 & 50,8 & 44,7 & $\mathrm{p}<.001$ & $\mathrm{p}<.001$ & $\mathrm{p}<.01$ \\
\hline
\end{tabular}

*Примечание. В скобках приведены средние показатели, полученные на выборке $\mathrm{n}=443$ [10].

Студентов с отрицательным показателем невоплоценности в интернете переживания, присущие этой форме отчуждения, характеризуют в наименьшей степени (значения показателей $\mathrm{He}$ воплощенность как виртуализация и Предпочтение интернета, которые суммирует общий показатель НВИ, хотя и низкие, но положительные), что позволяет обозначать их в дальнейшем как группу с низким уровнем невоплощенности. Итоговый отрицательный общий показатель НВИ отражает то обстоятельство, что в самоощущении этих пользователей адаптивное витальное воплощенное «Я», «подлинно основанное на своем теле» [11. С. 63], доминирует по отношению к бестелесному виртуальному «Я», а переживания бытия офлайн - по отношению к технологическому способу существования онлайн. Низкой приверженности интернету соответствует значение общего CLAS-балла в группе (43), пограничное между отсутствием интернет-зависимого поведения и склонностью к его возникновению [13]. Группа представляет интерес в том плане, что свойственные ей проявления невоплощенности можно рассматривать в качестве психологического последствия нормативного применения информационных технологий.

Две рассмотренные группы сопоставимы по размерам и составляют почти половину выборки, другая ее половина образует третью, в которой переживания невоплощенности в интернете представляют собой последствие как технологий, так и пользовательской активности, соответствующей склонности к интернет-зависимому поведению.

Далее невоплощенность в интернете в качестве новой технологической формы самоотчуждения рассматривалась в соотношении с известными проявлениями самоотчуждения и отчуждения, для че- 
го выявлялись значимые эффекты, оказываемые принадлежностью к группам, на отчуждение в разных сферах жизни и модальностях (табл. 3,4 ).

Таблица 3

Эффекты невоплощенности в интернете на отчуждение в разных сферах жизни и формах

\begin{tabular}{|c|c|c|c|c|c|}
\hline & & \multirow{2}{*}{$\frac{\text { MS }}{\text { Effect }}$} & \multirow{2}{*}{$\begin{array}{c}\text { MS } \\
\text { Error }\end{array}$} & \multicolumn{2}{|c|}{ Величины } \\
\hline & & & & $\mathrm{F}$ & $\mathrm{p}$ \\
\hline & $\begin{array}{c}\text { Общий показатель } \\
\text { отчуждения }\end{array}$ & 130875,5 & 757,45 & 172,8 & 0,000 \\
\hline \multirow{5}{*}{ 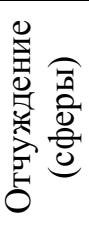 } & от общества & 3009,6 & 47,83 & 62,9 & 0,000 \\
\hline & от учебной деятельности & 5203,3 & 79,90 & 65,1 & 0,000 \\
\hline & от других людей & 5388,6 & 57,92 & 93,0 & 0,000 \\
\hline & от семьи & 5396,0 & 44,57 & 121,1 & 0,000 \\
\hline & от самого себя & 7816,2 & 67,34 & 116,1 & 0,000 \\
\hline \multirow{4}{*}{ 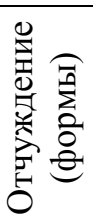 } & Вегетативность (VEGE) & 11949,8 & 67,89 & 176,0 & 0,000 \\
\hline & Бессилие (BESS) & 9959,6 & 77,71 & 128,2 & 0,000 \\
\hline & Нигилизм (NIHI) & 8877,6 & 79,90 & 111,1 & 0,000 \\
\hline & Авантюризм (AVAN) & 6576,5 & 119,41 & 55,1 & 0,000 \\
\hline
\end{tabular}

Общий показатель отчуждения убывает от группы с высоким уровнем невоплощенности в интернете к группе со средним и низким ее уровнем (табл. 4). Показатели генерализованного отчуждения в группах со средним и низким уровнем невоплощенности в интернете $(34,9$ и 27,7$)$ ниже 37,6 установленного Е. Осиным среднего значения для студенческой выборки [15], в то время как в группе «невоплощенных» он значительно выше $(44,4)$.

Таблица 4

Показатели отчуждения в разных сферах жизни и формах в группах студентов, различающихся выраженностью невоплощенности в интернете

\begin{tabular}{|c|c|c|c|c|c|c|c|}
\hline & \multirow[b]{2}{*}{$\begin{array}{c}\text { Группы, различающиеся } \\
\text { выраженностью НВИ }\end{array}$} & 1 & 2 & 3 & \multirow[t]{2}{*}{$1 \mathrm{vs} .2$} & \multirow[t]{2}{*}{1 vs.3 } & \multirow[t]{2}{*}{2 vs. 3} \\
\hline & & $\begin{array}{c}\text { Высокий } \\
\text { уровень }\end{array}$ & $\begin{array}{l}\text { Средний } \\
\text { уровень }\end{array}$ & $\begin{array}{l}\text { Низкий } \\
\text { уровень }\end{array}$ & & & \\
\hline \multicolumn{2}{|c|}{ Общий показатель отчуждения } & $44,4(7)^{*}$ & $34,9(4)$ & $27,7(2)$ & $\mathrm{p}<.001$ & $\mathrm{p}<.001$ & $\mathrm{p}<.001$ \\
\hline \multirow{5}{*}{ 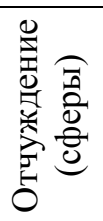 } & от общества & $34,5(7)$ & $27,0(5)$ & $21,5(2)$ & $\mathrm{p}<.001$ & $\mathrm{p}<.001$ & $\mathrm{p}<.001$ \\
\hline & от учебы & $47,8(6)$ & $37,9(4)$ & $31,5(3)$ & $\mathrm{p}<.001$ & $\mathrm{p}<.001$ & $\mathrm{p}<.001$ \\
\hline & в межличностных отношениях & $48,3(7)$ & $39,4(5)$ & $31,7(3)$ & $\mathrm{p}<.001$ & $\mathrm{p}<.001$ & $\mathrm{p}<.001$ \\
\hline & в семье & $40,4(7)$ & $30,4(4)$ & $22,8(3)$ & $\mathrm{p}<.001$ & $\mathrm{p}<.001$ & $\mathrm{p}<.001$ \\
\hline & от самого себя & $51,0(7)$ & $40,0(5)$ & $30,7(3)$ & $\mathrm{p}<.001$ & $\mathrm{p}<.001$ & $\mathrm{p}<.001$ \\
\hline \multirow{4}{*}{ 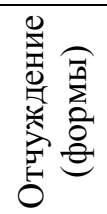 } & Вегетативность (VEGE) & 59,5 & 43,8 & 32,9 & $\mathrm{p}<.001$ & $\mathrm{p}<.001$ & $\mathrm{p}<.001$ \\
\hline & Бессилие (BESS) & 62,9 & 50,8 & 40,2 & $\mathrm{p}<.001$ & $\mathrm{p}<.001$ & $\mathrm{p}<.001$ \\
\hline & Нигилизм (NIHI) & 60,2 & 47,6 & 37,3 & $\mathrm{p}<.001$ & $\mathrm{p}<.001$ & $\mathrm{p}<.001$ \\
\hline & Авантюризм (AVAN) & 57,7 & 48,7 & 40,6 & $\mathrm{p}<.005$ & $\mathrm{p}<.001$ & $\mathrm{p}<.001$ \\
\hline \multicolumn{2}{|c|}{ Общий показатель отчуждения } & 44,4 & 34,9 & 27,7 & $\mathrm{p}<.001$ & $\mathrm{p}<.001$ & $\mathrm{p}<.001$ \\
\hline
\end{tabular}

* Примечание. В скобках приведены нормы в стенах, полученные на выборке московских школьников 10 11 классов и студентов [15].

Аналогичным образом от группы с высоким уровнем невоплощенности в интернете к группе со средним и низким ее уровнем убывают показатели отчуждения в разных сферах жизни студентов.

В групnе «невоплощенных» наиболее высокие показатели - показатели как самоотчуждения, так и отчуждения в семье, в межличностных отношениях, от общества и от учебы. Вероятно, крайнюю степень такого отчуждения демонстрирует особый тип молодых людей, получивших название «хикикомо- 
Невоплощенность в интернете как новая форма технологического самоотчуждения...

167 СЕРИЯ ФИЛОСОФИЯ. ПСИХОЛОГИЯ. ПЕДАГОГИКА

2021. Т. 31, вып. 2

ри». Первоначально оно подразумевало часть японской молодежи, не желающей взрослеть и вступать в общественную жизнь, сегодня «хикки» все более превращаются в международное явление, к формированию которого причастны информационные технологии [1]. На сходство этих молодых людей с шизоидами Р. Лэйнга указывают их психиатрические диагнозы, среди которых - шизофрения и расстройства аутистического спектра. Воспринимая жизнь как опасность, они нашли в искусственно созданной реальности и опосредствованном общении вполне удовлетворительную замену мечтам шизоида об анониме, инкогнито, чужестранце в чужом краю и его попыткам общаться только с незнакомцами, записываться под вымышленными именами в библиотеки и т. д. Не покидая родительский дом, хикикомори уклоняются от общения с самыми близкими людьми, избегают взаимодействия со сверстниками, ставят крест на своем образовании, чуждаются общественной жизни.

В группе «невоплощенных» самый высокий показатель - показатель вегетативности (vegetativeness), наиболее тяжелой формы отчуждения. Данное ей С. Мадди название намекает на предложенную Ламетри знаменитую метафору «человек-растение» и с тех пор многократно представленный в научной литературе тип человека, ведущего растительную жизнь, озабоченного лишь органическими нуждами. В этой группе также наиболее высокий по сравнению с другими группами показатель бессилия (powerlessnes), который C. Мадди в соответствии с существующей в экзистенциальной психологии традицией относит к субъективным проявлениям отчуждения. Бессилие означает осознание индивидом значения активного участия в жизни в сочетании с пониманием своей неспособности к этому [12]. На связь невоплощенности и бессилия указывает определение Ж. Гаррабе концепции Р. Лэйнга в качестве этапа разработки классической психоаналитической идеи о слабости «Я» [3]. Группа «невоплощенных» студентов также опережает две остальные группы по выраженности менее тяжелых форм неявного отчуждения: нигилизма (nihilism) и авантюризма (adventurousness). В первом случае дезориентацию в ценностях маскирует и компенсирует их отрицание, во втором - исполненная риска активность. Э. Эриксон указывал на связь нигилизма с обостряющейся в период юношеского кризиса идентичности потребностью в вере и идеалах, выражаемой громким и циничным неверием [20. С. 140]. Нигилизм близок по смыслу к негативизму, характеризующему промежуточный статус идентичности, в основе которого лежит отвержение принятых в обществе ценностей. А. Маслоу описывает молодых людей, страдающих духовной болезнью, взаимоотношения которых с миром нарушены и ненормальны. Их базовые потребности вполне удовлетворены, «но при этом в них можно заметить какой-то надлом, какое-то тотальное отрицание. ... Они уверены, что не в состоянии изменить мир к лучшему, и потому ограничиваются бессмысленными выходками и деструктивным протестом» [14. С. 205-206].

В обсуждаемой группе, так же как в группах студентов с промежуточным и отрицательным показателями невоплощенности в интернете, уровень выраженности новой формы технологического самоотчуждения соответствует уровню отчуждения в различных сферах жизни и модальностях, что соответствует господствующему в психологической литературе представлению о единой логике, в которой обнаруживаются разнообразные проявления отчуждения.

\section{Выводы}

Невоплощенность в интернете, подразумевающая отстранение пользователя от своего физического «Я», предполагает переживания им своей замкнутости в киберпространстве, утраты субстанциональности, реальности, жизненности «Я», иллюзорности всего существующего, альтернативу которым составляют переживания витального, «подлинно основанного на своем теле» «Я» в действительном мире. Мерой выраженности этих переживаний различаются три группы студентов, выявленные с помощью методики Невоплощенность в интернете (НВИ).

Полученные данные о значимых эффектах невоплощенности в интернете на ее частные измерения, интернет-зависимость и отчуждение позволили сделать заключения о том, что:

- высокий уровень новой технологической формы самоотчуждения в большей мере обязан своим происхождением характеру пользовательской активности (интернет-зависимости), в то время как низкий, соотносимый с нормативным использованием интернета, скорее представляет собой последствие собственно информационных технологий;

- уровень новой технологической формы самоотчуждения соответствует уровню отчуждения в различных сферах жизни офлайн, выраженности его модальностей разной степени тяжести и отражается на характере социализации, протекания юношеского кризиса идентичности в современных условиях. 


\section{СПИСОК ЛИТЕРАТУРЫ}

1. Войскунский А.Е., Солдатова Г.У. Эпидемия одиночества в цифровом обществе: хикикомори как культурно-психологический феномен // Консультативная психология и психотерапия. 2019. Т. 27, № 3. С. $22-43$. DOI: $10.17759 /$ cpp.2019270303

2. Выступление Маршалла Маклюэна на семинаре профессора Форсдэйла 17.07.78. [Электронный ресурс]. Тичерс-Колледж, Университет Коламбии, Нью-Йорк. URL: http://www.mcluhan.ru/quotations/marshallmaklyuen-na-seminare-professora-forsdejla/ (дата обращения 05.02.2021).

3. Гаррабе Ж. История шизофрении. М.-СПб., 2000. [Электронный ресурc]. URL: http://www.klex.ru/lb (дата обращения: 05.02.2021).

4. Герасимова А.А., Холмогорова А.Б. Общая шкала проблемного использования интернета: апробация и валидизация в российской выборке третьей версии опросника // Консультативная психология и психотерапия. 2018. T. 26, № 3. С. 56-79. DOI: 10.17759/cpp.2018260304

5. Дери М. Скорость убегания: Киберкультура на рубеже веков [Электронный ресурс]. Екатеринбург: Ультра. Культура; М.: ACT, 2008. 478 c. URL: http://www.marsexx.ru/lit/dery-escape.html (дата обращения: 05.02.2021).

6. Дорфман Л.Я. Воплощения и превращения как формы взаимодействия индивидуальности с миром. 1996. [Электронный pecypc]. URL: https://www.psychology.ru/library/00075.shtml (дата обращения: 05.02.2021).

7. К столетию Маршалла Маклюэна. [Электронный ресурс]. URL: http://www.svoboda.org/a/24269535.html (дата обращения: 05.02.2021).

8. Каминская Н.А. Исследования отчуждения физического «я» // Консультативная психология и психотерапия. 2016. T. 24, № 2. C. 8-28. DOI: 10.17759/cpp.20162402002

9. Коптева Н.В. Два способа «не быть собой» в концепциях К. Хорни и Р. Лэйнга // Вопросы психологии. 2016. № 3. С. 127-137.

10. Коптева Н.В., Калугин А.Ю., Дорфман Л.Я. Невоплощенность в интернете. Сообщение 1. Теоретические основания и конструкт. Сообщение 2. Психометрическая проверка инструментария [Текст, 2020 (не опубликовано)].

11. Лэйнг Р.Д. Расколотое «Я». Экзистенциальное исследование «нормальности» и безумия. Феноменология переживания и Райская птичка. М.: ИОИ, 2017. 350 с.

12. Мадди С.Р. Смыслообразование в процессе принятия решений // ПЖ. 2005. Т. 26, № 6. С. 87-101.

13. Малыгин В.Л., Феклисов К.А., Антоненко А.А., Смирнова Е.А., Хомерики Н.С. Интернет-зависимое поведение. Критерии и методы диагностики: учеб. пособие. М.: МГМСУ, 2011. 32 с.

14. Маслоу А. Дальние пределы человеческой психики. СПб.: Евразия, 1997. 430 с.

15. Осин Е.Н. Смыслоутрата как переживание отчуждения: структура и диагностика: дис. ... канд. психол. наук. М., $2007.180 \mathrm{c}$.

16. Райкрофт Ч. Критический словарь психоанализа. СПб.: Восточно-Европейский институт психоанализа, 1995. 288 c.

17. Рассказова Е.И., Емелин В.А., Тхостов А.Ш. Диагностика психологических последствий влияния информационных технологий на человека. М.: Акрополь, 2015. 115 с.

18. Сирота Н.А., Московченко Д.В., Ялтонский В.М., Ялтонская А.В. Разработка русскоязычной версии опросника проблемного использования социальных сетей // Консультативная психология и психотерапия. 2018. T. 26, № 3. C. 33-55. DOI: 10.17759/cpp.2018260303

19. Фромм Э. Анатомия человеческой деструктивности. М.: Республика, 1994. 447 с.

20. Эриксон Э. Идентичность: юность и кризис. М.: Издательская группа «Прогресс», 1996. 344 с.

21. Bell D. An introduction to cybercultures. London, New York, NY: Routledge, 2001. 246 p.

22. Chen Y.F., Peng S.S. University students' Internet use and its relationships with academic performance, interpersonal relationships, psychosocial adjustment, and self-evaluation // Cyberpsychol Behav. 2008. Aug; 11 (4). P. $467-469$.

23. Ju-Yu Yen, Cheng-Fang Yen, Cheng-Sheng Chen, Tze-Chun Tang, Chih-Hung Ko. The Association between Adult ADHD Symptoms and Internet Addiction among College Students: The Gender Difference CyberPsychology \& Behavior. April 2009, Vol. 12, no. 2. P. 187-191.

24. Laing R.D. The divided Self. An existential study in sanity and madness. UK: Penguin Books, 2010.218 p.

25. Rheingold H. The Virtual Community: Homesteading on the Electronic Frontier. Reading, MA: Addison Wesley, 1993. 325 p. URL: http://www.rheingold.com/vc/book/5.html (accessed: 05.02.2021).

26. Turkle S. Life on the screen: Identity in the age of the Internet. New York: Simon \& Schuster. 1995. 247 p.

Коптева Наталия Васильевна, доктор психологических наук, доцент, профессор кафедры практической психологии Пермский государственный гуманитарно-педагогический университет 614990, Россия, г. Пермь, ул. Сибирская, 24

E-mail:kopteva@pspu.ru 


\section{N.V. Kopteva \\ DISEMBODIMENT ON THE INTERNET AS A NEW FORM OF TECHNOLOGICAL SELF-ALIENATION (BASED ON THE STUDY OF STUDENTS OF HUMANITARIAN INSTITUTES OF HIGHER EDUCATION)}

DOI: $10.35634 / 2412-9550-2021-31-2-160-169$

Phenomenon of disembodiment of users of information technologies in virtual reality, in particular as a special form of self-alienation, was already noted by the first representatives of cyber culture. However, psychologists have not properly analyzed it yet, perhaps, due to the usual peripheral position of the problem of disembodiment of a physical body in psychology. In the present study we continue to develop our theoretical and empirical construct of the Disembodiment on the Internet (N.V. Kopteva, A.Yu. Kalugin, L.Ya. Dorfman) as a psychological impact of the use of contemporary information technologies in areas related to self-alienation and alienation. The construct is based on the conception of unembodiment of the mental self from the body by a British psychiatrist R. Laing, which is considered to be one of the fundamental psychiatric conceptions of disembodiment of the physical self. R. Laing's description of the 'detachment' of schizoids from their own body helps understand the specifics of existential positions of embodiment - disembodiment determined by sociocultural, technological factors and choices made by individuals themselves. Our study was performed on a sample of active Internet users - students of humanitarian institutes of higher education (aged from 17 to 25 years) - with the use of the Disembodiment on the Internet diagnostic procedure. We revealed groups that differentiated in the severity of disembodiment and created their psychological portraits according to patterns of disembodiment, which include experience of unbodiliness of the virtual self, incompleteness and secondariness of the technological way of being limited by the Internet environment and Internet addiction. We also empirically detected the effects of disembodiment on the alienation of students in different aspects of their life (from who they are, from their families, in interpersonal communication, from their studies and the society) ranging from 'vegetativeness' to adventurism.

Keywords: psychological consequences of the use of information technologies, disembodiment of the physical self, disembodiment on the Internet, self-alienation, alienation.

Kopteva N.V., Doctor of Psychology, Associate Professor, Professor at Department of Practical Psychology Perm State Humanitarian Pedagogical University

Sibirskaya st., 24, Perm, Russia, 614990

E-mail: kopteva@pspu.ru 